\title{
Hydrocracking of LDPE Plastic Waste into Liquid Fuel over Sulfated Zirconia from a Commercial Zirconia Nanopowder
}

\author{
LATIFAH HAULI $^{1}$, KARNA WIJAYA ${ }^{1 *}$ and AKHMAD SYOUFIAN ${ }^{1}$ \\ 1'Department of Chemistry, Faculty of Mathematics and Natural Sciences, \\ Universitas Gadjah Mada, Sekip Utara Bulaksumur, Yogyakarta, 55281, Indonesia. \\ ${ }^{*}$ Corresponding author E-mail: karnawijaya@ugm.ac.id \\ http://dx.doi.org/10.13005/ojc/350113
}

(Received: December 04, 2018; Accepted: January 06, 2019)

\begin{abstract}
Hydrocracking of LDPE plastic waste into liquid fuel was conducted by using sulfated zirconia (SZ) and $\mathrm{Cr}$ metal supported on $\mathrm{SZ}(\mathrm{Cr} / \mathrm{SZ})$ catalysts. Catalysts were prepared and characterized by SEM-EDS, SAA, and TGA-DTA. The liquid produced was characterized by GC-MS. The characterization result showed the sulfate group was successfully impregnated on $\mathrm{ZrO}_{2}$ nanopowder with the higher content of $\mathrm{S}$ and $\mathrm{O}$ than $\mathrm{ZrO}_{2}$ and then decreased after addition of $\mathrm{Cr}^{2}$ metal as confirmed in SEM-EDS result. All catalysts were in mesoporous material as observed by SAA characterization and also showed the highest specific surface area of $\mathrm{Cr} / \mathrm{SZ}$ catalyst of $14.56 \mathrm{~m}^{2} \mathrm{~g}^{-1}$. The catalytic activity increased by the presence of $\mathrm{Cr}$ on SZ with liquid produced about $40.15 \%$. Hydrocracking process also increased the gasoline fraction and the highest gasoline fraction was produced by $\mathrm{Cr} / \mathrm{SZ}$ catalyst at about $89.91 \%$.
\end{abstract}

Keywords: Sulfated zirconia, Catalyst, Low density polyethylene plastic(LDPE), Fuel.

\section{INTRODUCTION}

Plastic was polymeric compound that was very much found in the activities of human life so that the increasing amount of plastic used also had a significant impact in the increasing of plastic waste produced $^{1,2}$. Plastic waste which accumulated could cause the environmental problems and became a threat because the plastic waste was very difficult to disintegrate in the soil and required a very long time to be degraded ${ }^{3,4}$. Hydrocracking was one of the most promising and highly developed technique to break plastic polymer. This process could be solutions to overcome the problem of plastic waste and also the lack of the fuel availability because it was potential to crack the plastic into liquid fue ${ }^{5,6}$. It also usually began with the pyrolysis as initial step ${ }^{7}$.

In hydrocracking, heterogeneous catalyst was more widely used and developed because of their high thermal stability, safe used, selectivity to the product, environmentally friendly, and reusable. Heterogeneous catalyst that was currently being developed to convert polymers was the groups of metal oxides such as zirconia $\left(\mathrm{ZrO}_{2}\right) . \mathrm{ZrO}_{2}$ had the good characteristic i.e. the corrosion resistant,

This is an Open Access article licensed under a Creative Commons license: Attribution 4.0 International (CC- BY). Published by Oriental Scientific Publishing Company @ 2018 
high thermal stability, low thermal conductivity so that material was very potential to be used in many applications $^{8-12}$.

Modification of $\mathrm{ZrO}_{2}$ material with the strong acid such as sulfate acid had proved an increasing of the surface acidity and activity ${ }^{13}$. Several methods for preparation of SZ catalyst had also been successfully investigated could increase of acidity ${ }^{14-16}$. In this study, the wet impregnation method was conducted to get the SZ catalyst from a commercial $\mathrm{ZrO}_{2}$ nanopowder then $\mathrm{Cr}$ metal was impregnated to SZ by reflux method. The catalyst obtained was tested in hydrocracking process of low-density polyethylene (LDPE) plastic waste in application. Several catalytic properties of those catalysts, the yield conversion, and the selectivity of the liquid produced also were learned in this research. The used of the synthesis method for these catalysts and development of the catalysts test in plastic conversion to liquid fuel had never been done before.

\section{EXPERIMENTAL}

\section{Materials}

Commercial zirconia nanopowder was supplied from China (purity 99\%). Sulfuric acid (98\%), ammonia (25\%), and chromium (III) nitrate nonahydrate was obtained from Merck \& Co. The low density polyethylene (LDPE) plastics were collected from the final disposal in Yogyakarta. Hydrogen gas was supplied by PT. Samator Gas Industry.

\section{Preparation of SZ catalyst}

Sulfated zirconia catalyst was prepared by wet impregnation method. $\mathrm{ZrO}_{2}$ nanopowder about $10 \mathrm{~g}$ was added into $150 \mathrm{~mL} 0.8 \mathrm{M} \mathrm{H}_{2} \mathrm{SO}_{4}$ solution then stirred for $24 \mathrm{~h}$ and calcined for $4 \mathrm{~h}$ at $600{ }^{\circ} \mathrm{C}^{14}$. $\mathrm{SZ}$ catalyst which obtained then dried in an oven at $100^{\circ} \mathrm{C}$ for overnight. Catalyst was crushed and sieved in a 250 mesh sieve. Catalyst produced was labeled with Sulfated zirconia.

Chromium (Cr) metal was impregnated into SZ catalyst by wet impregnation method using salt of chromium (III) nitrate nonahydrate $(1.0 \%(\mathrm{w} / \mathrm{w}))$, dissolved in $100 \mathrm{~mL}$ of distilled water and added SZ catalyst, then refluxed at $90^{\circ} \mathrm{C}$ for 4 hours. Catalysts were dried in the oven at $100{ }^{\circ} \mathrm{C}$ for overnight, calcined at $600{ }^{\circ} \mathrm{C}$, then reduced by flowing $\mathrm{H}_{2}$ gas at $400{ }^{\circ} \mathrm{C}$ for $2 \mathrm{~h}$ with a flow rate of $10 \mathrm{~mL} /$ minutes. Catalyst produced was labeled with $\mathrm{Cr} / \mathrm{SZ}$. The acidity of all catalysts was determined by gravimetric method with ammonia adsorption.

\section{Hydrocracking experiment}

The plastic raw material was cleaned by washing, dried then cut into small pieces. Plastic was heated at $300-400{ }^{\circ} \mathrm{C}$ for $4 \mathrm{~h}$ in the pyrolysis reactor. The gas produced in the pyrolysis reactor was condensed into a liquid phase through a condenser. The liquid produced from pyrolysis was hydrocracked at $300{ }^{\circ} \mathrm{C}$ for $1 \mathrm{~h}$ under $\mathrm{H}_{2}$ gas stream with a flow rate of $10 \mathrm{~mL} /$ minute. The hydrocracking process was conducted in the hydrocracking microreactor by using the catalyst with the feed/catalyst ratio of 100. The conversion yield was calculated by using the equations:

$$
\begin{aligned}
& \text { Liquid product }(w t \%)=\frac{\text { weight of liquid yield }}{\text { weight of feed }} \times 100 \% \\
& \text { Residue product }(w t \%)=\frac{\text { weight of residdue of feed }}{\text { weight of feed }} \times 100 \% \\
& \text { Solid product }(w t \%)=\frac{\text { weight of solid of liydtoctracking process }}{\text { weight of feed }} \times 100 \%
\end{aligned}
$$

Gas product $(w t \%)=100 \%-w t \%$ (liquid +residue + solid)

The liquid product from pyrolysis and hydrocracking of LDPE plastic waste was characterized by GC-MS.

\section{Instrumentation}

The surface morphology of $\mathrm{ZrO}_{2}$ and $\mathrm{SZ}$ catalysts was investigated by scanning electron microscope (SEM, JEOL JSM-6510) which equipped with the energy dispersive spectrometer (EDS, JED-2300) for detecting the elements of these catalysts. The specific surface area, pore volume, and pore diameter were characterized by surface area analyzer (SAA, Quantachrome NovaWin Series version 11.0). The sample was outgassed for $4 \mathrm{~h}$ at $200{ }^{\circ} \mathrm{C}$. The physical adsorption of $\mathrm{N}_{2}$ gas was conducted at batch temperature $77.3 \mathrm{~K}$. The surface parameter such as specific surface area was calculated by using the Brunauer-Emmett-Teller (BET) method while the average pore diameter was calculated by using the Barrett-Joyner-Halenda 
(BJH) method. Acidity of catalysts was identified by fourier transform infrared spectroscopy (FTIR, Shimadzu Prestige-21) with a $\mathrm{KBr}$ disc technique in range $4000-500 \mathrm{~cm}^{-1}$. Thermogravimetric analysis (TGA) and differential thermal analysis (DTA) for SZ catalyst were also conducted by using DTG-60 instrument which operated range from room temperature to $600{ }^{\circ} \mathrm{C}$ in air with flow rate $30 \mathrm{~mL} /$ minutes. The liquid product was analyzed by using gas chromatography-mass spectrometer (GC-MS, Shimadzu QP 2010S) with the column length about $30 \mathrm{~m}$ and helium as a carrier gas.

\section{RESULTS AND DISCUSSION}

\section{SEM-EDS characterization}

Figure 1 showed the morphology images of $\mathrm{ZrO}_{2}$ nanopowder and SZ catalysts which observed by SEM. SEM result indicated the different morphology surface feature from before and after addition of sulfate. The presence of agglomeration particle occurred after sulfate addition as shown in Fig.1. SEM-EDS could not identify $\mathrm{Cr}$ particles. However, it observed the different size and disordered shape of all catalysts. The elements of $\mathrm{Zr}, \mathrm{O}$, and $\mathrm{S}$ in the catalysts which observed by EDS were presented in Table 1. EDS result showed the content of $O$ and $S$ increased after addition of sulfate and decreased after impregnating of $\mathrm{Cr}$ metal. It indicated that $\mathrm{ZrO}_{2}$ was successfully impregnated by sulfate and $\mathrm{Cr}$ metal ${ }^{17}$.

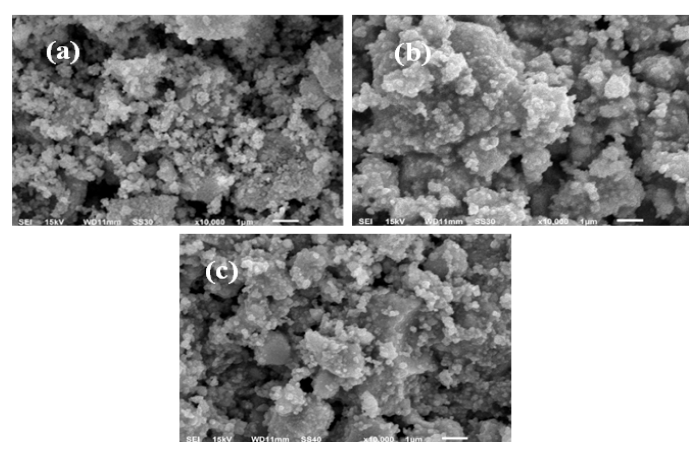

Fig.1. SEM images of (a) $\mathrm{ZrO}_{2}$ (b) $\mathrm{SZ}$ (c) $\mathrm{Cr} / \mathrm{SZ}$

Table 1: Elements analysis (EDS) of catalysts

\begin{tabular}{cccc}
\hline Sample & \multicolumn{3}{c}{ Mass (\%) } \\
& $\mathrm{Zr}$ & $\mathrm{O}$ & $\mathrm{S}$ \\
\hline $\mathrm{ZrO}_{2}$ & 71.33 & 28.06 & 0.54 \\
$\mathrm{SZ}$ & 67.47 & 30.41 & 2.09 \\
$\mathrm{Cr} / \mathrm{SZ}$ & 70.75 & 27.79 & 0.54 \\
\hline
\end{tabular}

\section{SAA characterization}

The specific surface area, average pore diameter, and total pore volume of catalysts were presented in Table 2. The specific surface area of SZ was smaller than $\mathrm{ZrO}_{2}$ nanopowder. This decreasing occurred because the sulfate group loaded into the pores of $\mathrm{ZrO}_{2}$ nanopowder at impregnation process ${ }^{14}$. Possibility of surface area reduction also caused by sulfate group which was not evenly distributed to the surface and formed agglomeration with $\mathrm{ZrO}_{2}{ }^{18}$. Specific surface area increased after addition of $\mathrm{Cr}$ metal on SZ catalyst. This occurred because $\mathrm{Cr}$ metal was evenly distributed on the surface of catalyst. There were no significant changes from the total pore volume and the average pore diameter. The presence of sulfate which possibly entered the pore could slightly widen the pore size and thus increased the total pore volume. The sulfate group which did not fill the small pores could make the overall average pore diameter would be small.

Figure 2 showed the isotherm adsorptiondesorption of $\mathrm{N}_{2}$ gas. In this study, all catalysts were in type IV isotherm which essentially indicated mesoporous material (between 25 and $55.5 \AA$ ) as according to IUPAC classification. It also confirmed by average pore diameter as shown in Table 2 . Sing et al., ${ }^{19}$ had reported that type IV isotherm was indicated the adsorption from monolayer to multilayer. Mesoporous material characteristic of was the hysteresis loop which attributed to the capillary condensation. In this study, $\mathrm{ZrO}_{2}$ and $\mathrm{Cr} / \mathrm{SZ}$ catalysts had the hysteresis of type $\mathrm{H}_{4}$ loop while $\mathrm{SZ}$ catalyst had the hysteresis of type $\mathrm{H}_{3}$ loop. Type $\mathrm{H}_{3}$ loop, it seem likely did not show the limiting adsorption at high P/PO. It was associated with the plate-like particle aggregates that created the slit-shaped pores. Type $\mathrm{H}_{4}$ loop was attributed to the narrow slit-like pore.

Table 2: Textural properties of catalysts

\begin{tabular}{cccc}
\hline Sample & $\begin{array}{c}\mathrm{S}_{\mathrm{BET}} \\
\left(\mathrm{m}^{2} \mathrm{~g}^{-1}\right)\end{array}$ & $\begin{array}{c}\text { Average pore } \\
\text { diameter }(\AA)\end{array}$ & $\begin{array}{c}\text { Total pore } \\
\text { volume }\left(\mathrm{cm}^{3} \mathrm{~g}^{-1}\right)\end{array}$ \\
\hline $\mathrm{ZrO}_{2}$ & 12.27 & 36.98 & 0.07 \\
$\mathrm{SZ}$ & 7.79 & 36.84 & 0.08 \\
$\mathrm{Cr} / \mathrm{SZ}$ & 14.56 & 36.96 & 0.07 \\
\hline
\end{tabular}




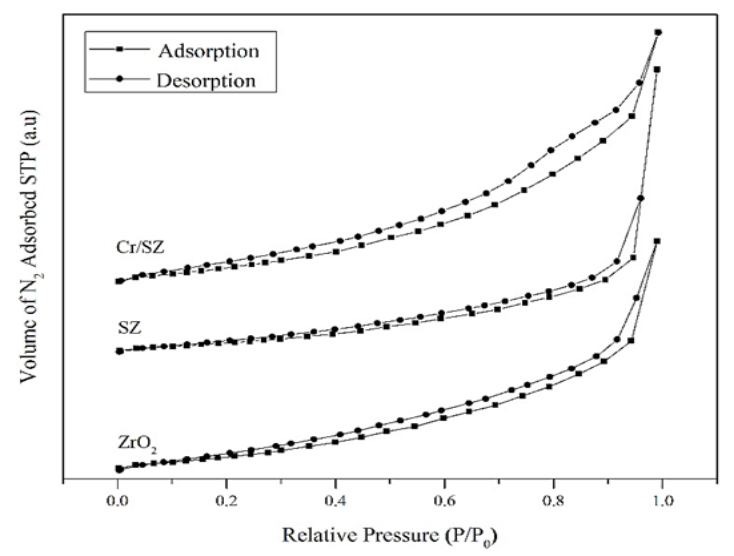

Fig. 2. Ishoterm adsorption-desorption of catalysts

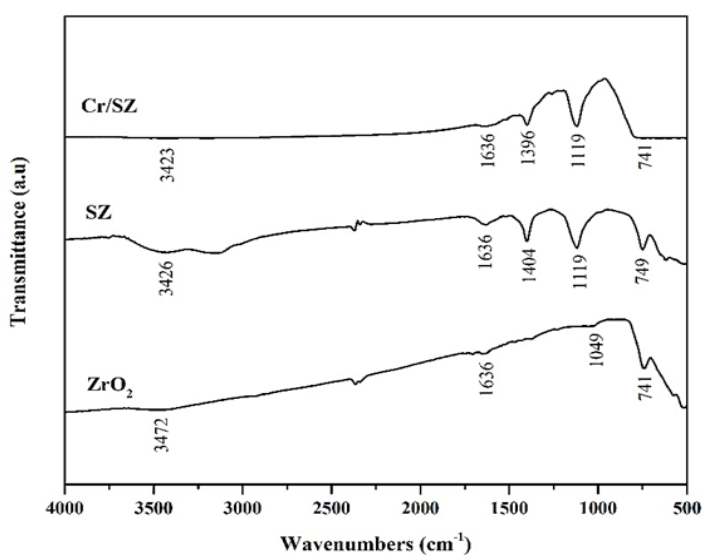

Fig. 3. FTIR of ammonia sorption on catalysts

Table 3: Acidity value of catalyst

\begin{tabular}{lc}
\hline Sample & Acidity value $(\mathrm{mmol} / \mathrm{g})$ \\
\hline $\mathrm{ZrO}_{2}$ & 0.06 \\
$\mathrm{SZ}$ & 3.81 \\
$\mathrm{Cr} / \mathrm{SZ}$ & 8.22 \\
\hline
\end{tabular}

FTIR spectra of ammonia sorption on $\mathrm{ZrO}_{2}, \mathrm{SZ}$, and $\mathrm{Cr} / \mathrm{SZ}$ catalysts was presented in Fig. 3. Ammonia adsorbed on Brønsted acid sites was characterized with vibration band at $1404 \mathrm{~cm}^{-1}$ while the ammonia adsorbed on Lewis acid sites was detected around at $1119 \mathrm{~cm}^{-1} 21-22$. The presence of both Brønsted and Lewis acid sites could increase acidity of catalysts ${ }^{23}$. It also was investigated from acidity value in Table 3. Acidity of $\mathrm{SZ}$ was higher than $\mathrm{ZrO}_{2}$, it indicated that sulfate group was successfully impregnated on $\mathrm{ZrO}_{2}{ }^{14}$. Acidity of $\mathrm{Cr} / \mathrm{SZ}$ catalyst was highest, it indicated that $\mathrm{Cr}$ metal was successfully impregnated on $\mathrm{SZ}$ catalyst. It was confirmed from acidity value of $\mathrm{Cr} / \mathrm{SZ}$ catalyst about $8.22 \mathrm{mmol} / \mathrm{g}$.
Lewis acid sites was available from the empty d-orbital of $\mathrm{Cr}$ metal which it could receive free electron pair from nitrogen of ammonia. Because of it, acidity value of $\mathrm{Cr} / \mathrm{SZ}$ catalyst was so high.

\section{Thermal analysis characterization}

TGA and DTA of SZ catalyst were presented in Fig.4. TGA showed the weight loss above $200^{\circ} \mathrm{C}(0.82 \mathrm{mg})$. It attributed to dehydration of absorbed water which also was showed at DTA characterization as endotherm process ${ }^{24}$. Amalia et al., ${ }^{25}$ had reported that decomposition of sulfate could occur at the high temperature from 873-1213 K. Hiromi et al., ${ }^{26}$ also had reported that decomposition of surface sulfate began to occur above $773 \mathrm{~K}$ and the weight would decrease gradually until $1273 \mathrm{~K}$. In this study, the decomposition of sulfate had not been detected because of the short temperature range used. The result showed that the material was stable up to $600^{\circ} \mathrm{C}^{11}$. That result also appeared another endothermic low intensity peak around at $340^{\circ} \mathrm{C}$ as shown at DTA characterization and could be attributed to dehydroxylation process ${ }^{27}$.

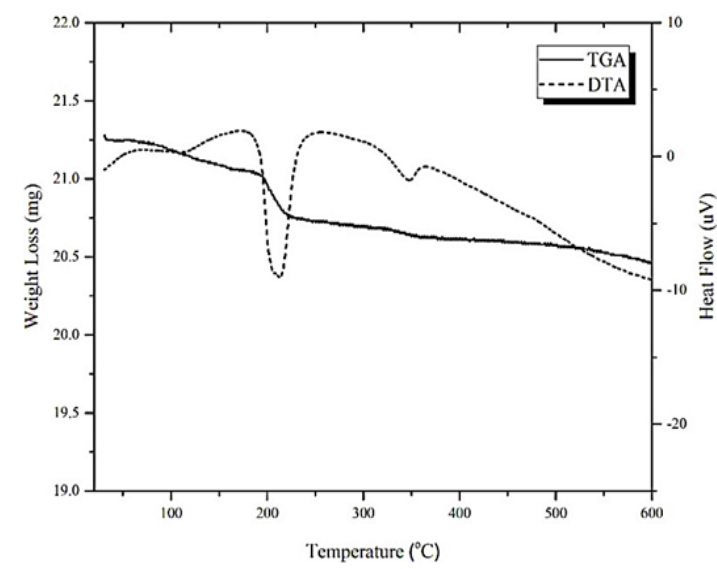

Fig. 4. TGA and DTA of SZ catalyst

\section{Catalysts activity}

The activity of $\mathrm{ZrO}_{2}, \mathrm{SZ}$, and $\mathrm{Cr} / \mathrm{SZ}$ catalysts was conducted for hydrocracking of LDPE plastic waste. Pyrolysis process of LDPE plastic waste into liquid was conducted as the first step to prepare feed then was continued with a catalytic hydrocracking process to get results with a fraction that was lighter than the liquid fuel produced previously ${ }^{28}$. The conversion of LDPE plastic waste at temperature of $300{ }^{\circ} \mathrm{C}$ was showed in Fig. 5. The hydrocracking of LDPE plastic waste produced gas, liquid, residue, and solid yield. The highest liquid yield was produced 
by $\mathrm{Cr} / \mathrm{SZ}$ catalyst of $40.15 \%$ while the highest gas and residue yields were produced by $\mathrm{ZrO}_{2}$ catalyst of $38.07 \%$ and $44.69 \%$, respectively. One of the factor could influence catalytic activity was an acidity of the catalyst which increased the presence of the Lewis and Brønsted acid sites ${ }^{23}$. It had been previously mentioned that the presence of $d$-orbital of chromiummetal which could increase the acidity and make it easy to bind with radical hydrogen from homolysis reaction of hydrogen gas in hydrocracking process. The wider surface area of $\mathrm{Cr} / \mathrm{SZ}$ catalyst also made it easier to interact with much reactant which could break the macromolecules of plastic polymers on the external surface of catalyst through a carbonium ion mechanism ${ }^{29}$. It caused the activity of $\mathrm{Cr} / \mathrm{SZ}$ catalyst became greater and also affected the amount of liquid produced. It was proven that $\mathrm{Cr} / \mathrm{SZ}$ catalyst could increase the liquid yield in hydrocracking experiment.

The high temperature of hydrocracking process could cause the formation of radical compounds due to the reaction of homolysis which these radical compounds produced could bind to the other radical compounds then formed the short-chain carbon compounds. This compound usually was in the gas phase ${ }^{30}$. Therefore, in this study also still produced a lot of gas yields. Residue yield from hydrocracking process for all catalysts was still much. However, the use of chromium supported on SZ catalysts could reduce residue yield. The result also showed that all catalyst produced the solid yield. The contact of catalyst with hydrocarbons at high temperatures could form coke deposits on the surface and loss of sulfate group ${ }^{20}$. This caused $\mathrm{Cr} / \mathrm{SZ}$ catalyst had the highest solid yield.

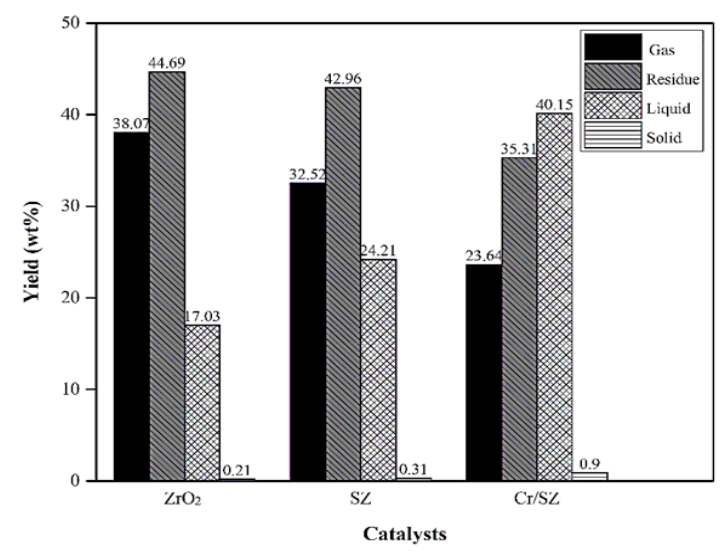

Fig. 5. Conversion yield from hydrocracking of LDPE Plastic
Selectivity of liquid yield from pyrolysis and hydrocracking process also presented in this research. The selectivity of pyrolysis product was presented in Fig. 6 . The result showed that the highest selectivity from pyrolysis process was in diesel fraction (C13-C20) of $52.27 \%$. Pyrolysis process also still produced heavy fraction $(C>20)$ of $0.41 \%$. Fig. 7 showed the selectivity of liquid product from catalytic hydrocracking process. The result showed the decreasing of diesel fraction and the increasing gasoline fraction after hydrocracking with $\mathrm{ZrO}_{2}, \mathrm{SZ}$, and $\mathrm{Cr} / \mathrm{SZ}$ catalysts. The heavy fraction also did not appear in this result. Based on the selectivity result, catalytic hydrocracking process produced the high gasoline fraction as desired.

Figure 7 also exhibited the highest gasoline fraction selectivity was produced by $\mathrm{Cr} / \mathrm{SZ}$ catalyst about $89.91 \%$. This result also proved that the presence of $\mathrm{Cr}$ metal on SZ catalyst increased the liquid product from hydrocracking of LDPE plastic waste and also selectivity for gasoline fraction produced.

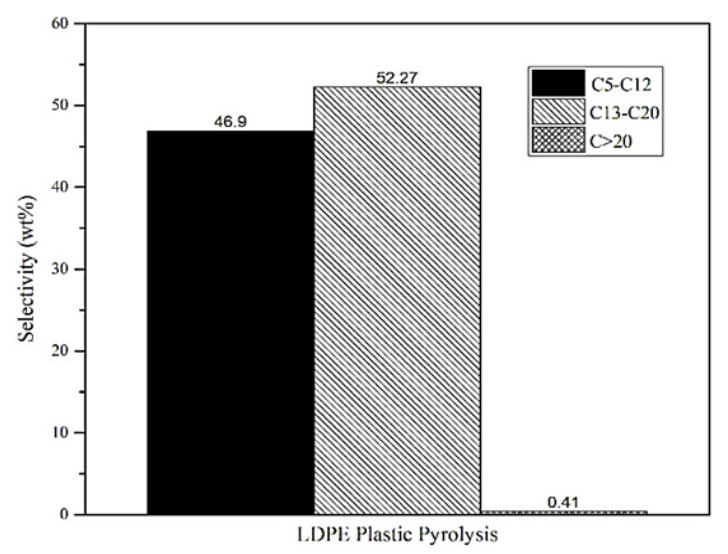

Fig. 6. Selectivity of liquid yield from LDPE pyrolysis

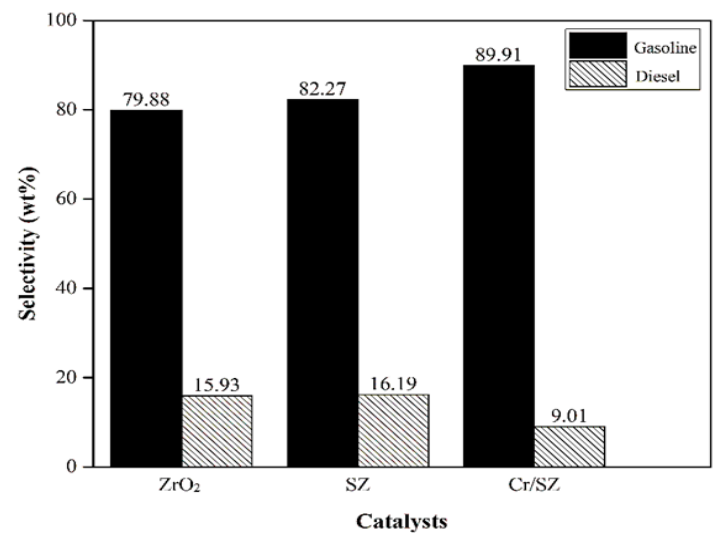

Fig. 7. Selectivity of liquid yield from hydrocracking of LDPE plastic waste 


\section{CONCLUSION}

Sulfate group was successfully impregnated on $\mathrm{ZrO}_{2}$ nanopowder with the higher content of $\mathrm{S}$ and $\mathrm{O}$ than $\mathrm{ZrO}_{2}$ catalyst and decreased after addition of chromium metal as confirmed in SEM-EDS result. All catalysts was in mesoporous material as observed by SAA characterization and also showed the highest specific surface area of $\mathrm{Cr} / \mathrm{SZ}$ catalyst of $14.56 \mathrm{~m}^{2} \mathrm{~g}^{-1}$. Hydrocracking of LPDE plastic waste produced the highest liquid product which conducted by using $\mathrm{Cr} / \mathrm{SZ}$ catalyst about $40.15 \%$ and it could reduce residue and gas yield. Based on selectivity, the pyrolysis process still produced the high diesel fraction in the liquid yield and the gasoline fraction increased after hydrocracking process from using all catalysts. The highest gasoline fraction was produced by $\mathrm{Cr} / \mathrm{SZ}$ catalyst about $89.91 \%$.

\section{Conflict of interest}

Authors have no conflict of interest to declare.

\section{ACKNOWLEDGMENT}

This work was financially supported by Indonesia Ministry of Research, Technology, and Higher Education under program of PMDSU Batch II (Contract number: 2028/UN1/DITLIT/DIT-LIT/ LT/2018).

\section{REFERENCES}

1. Hazrat, M. A.; Rasul, M.G.; Khan, M. M. K. Procedia Eng., 2015, 105, 865-876.

2. Buekens, A.; Huang, H. Resour Conserv Recycl., 1998, 23, 163-181.

3. Sarker, M.; Rashid, M. M.; Rahman, M. S.; Molla, M. J Environ Prot., 2012, 03, 700-708.

4. Hamid, S.H.; Amin, M. B. J. Appl Polym Sci., 1995, 55, 1385-1394.

5. Demirbas, A. J. Anal Appl Pyrolysis., 2004, 72, 97-102.

6. Kunwar, B.; Cheng, H. N.; Chandrashekaran, S. R.; Sharma, B. K. Renew Sustain Energy Rev., 2016, 54, 421-428.

7. Syamsiro, M.; Saptoadi, H.; Norsujianto, T. Energy Procedia., 2014, 47, 180-188.

8. Siddiqui, M. R. H.; Al-wassil, A. I.; Al-Otaibi, A. M.; Mahfouz, R. M. Mater Res., 2012, 15, 986-989.

9. Sivasamy, A.; Cheah, K. Y.; Fornasiero, P.; Kemausuor, F.; Zinoviev, S.; Miertus, S. Chem Sustain Energy Mater., 2009, 2, 278-300.

10. Fatimah, I.; Rubiyanto, D.; Kartika, N. C. Indones. J. Chem., 2016, 16, 8-13.

11. Patel, A.; Brahmkhatri, V.; Singh, N. Renew Energy., 2013, 51, 227-233.

12. Raissi, S.; Kamoun, N.; Younes, M.K.; Ghorbel, A. React Kinet Mech Catal., 2015, 115, 499-512.

13. Jin, T.; Yamaguchi, T.; Tanabe, K. J. Phys Chem., 1986, 90, 4194-4196.

14. Hauli, L.; Wijaya, K.; Armunanto, R. Orient. J. Chem., 2018, 34, 1559-1564.

15. Yu, S.;Jiang, P.;Dong, Y.;Zhang, P.;Zhang, Y.;Zhang, W. Bull. Korean Chem. Soc., 2012, 33, 524-528.

16. Li, B.; Gonzalez, R. D. Ind. Eng. Chem. Res.
1996, 35, 3141-3148.

17. Utami, M.; Wijaya, K.; Trisunaryanti, W. Key Eng. Mater., 2017, 757, 131-137.

18. Utami, M.;Wijaya, K.; Trisunaryanti, W. Mater. Chem. Phys., 2018, 213, 548-555.

19. Sing, K.S.W.; Everett, D.H.;Haul, R.A.W.;Moscou, L.; Pierotti, R. A.; Rouquerol, J.; Siemieniewska, T. J. Pure Appl. Chem., 1985, 57, 603-619.

20. Aboul-gheit, A. K.; Gad, F. K.; Abdel-aleem, G. M.; El-desouki, D. S. Egypt J Pet., 2014, 23, 303-314.

21. Sohn, J. R.; Kwon, T. D.; Kim, S. B.. Bull. Korean Chem. Soc., 2001, 22, 1309-1315.

22. Jiang, K.; Tong, D.; Tang, J.; Song, R.; Hu, C. Applied Catal. A. Gen., 2010, 389, 46-51.

23. Kustov, L. M.; Kazansky, V. B.; Figueras, F.; Tichit, D. J. Catal., 1994, 150, 143-149.

24. Srinivasan, R.; Keogh, R. A. J. Catal., 1995, 153, 123-130.

25. Luz, A.; Pereira, C.; Gustavo, S.; Albornoz, A Applied Catal. A., 2008, 334, 187-198.

26. Matsuhashi, H.; Nakamura, H.; Ishihara T,; Iwamoto, S.; Kamiya, Y. Applied Catal. A., 2009, 360, 89-97.

27. Aboul-Gheit, A. K.; El-Desouki, D. S.; AbdelHamid, S. M.; Ghoneim, A.; Ibrahim, A. H.; Gad, F. K. Egypt J. Chem., 2012, 527, 509-527.

28. Sriningsih, W.; Saerodji, M. G.; Trisunaryanti, W.; Armunanto, R.; Falah, I. Procedia Environ Sci., 2014, 20, 215-224.

29. Qader, S. A.; Hill, G. R. IEC Process Des Dev., 1969, 8, 456-461.

30. Pongsendana, M.; Trisunaryanti, W.; Artanti, F. W.; Falah, I. Korean J. Chem. Eng., 2017, 34, 2591-2596. 